\title{
Nas tramas do discurso: sentidos sobre biblioteca, leitura e pesquisa escolar
}

\author{
Ludmila Ferrarezi \\ Lucília Maria Sousa Romão \\ Universidade de São Paulo - USP. Brasil
}

\section{ANÁLISE / ANALYSIS}

\begin{abstract}
Resumo
A partir dos pressupostos teóricos da Análise do Discurso de linha francesa, observamos como as condições sócio-históricoideológicas afetam a constituição/formulação/circulação dos sentidos, que podem ser naturalizados, delineando uma determinada imagem de biblioteca, leitura e pesquisa escolar. Para tanto, fizemos um breve percurso histórico sobre o desenvolvimento das bibliotecas escolares brasileiras, marcado por sentidos de falta e restrição, que são atualizados pelo funcionamento da memória discursiva, ecoando nos dizeres contemporâneos sobre essa instituição e as atividades nela realizadas. Tais sentidos apontam a importância de se colocar em prática uma mudança de postura por parte dos professores e bibliotecários, abrindo espaço para práticas (discursivas) de leitura e pesquisa mais críticas, criativas e questionadoras, tanto na sala de aula, quanto na biblioteca, que é muito mais do que um depósito ou uma coleção de livros.
\end{abstract}

Palavras-chave

Discurso; Memória; Bibliotecas escolares; Leitura; Pesquisa escolar

\section{In the webs of discourse: senses on scholar library, reading and research}

\begin{abstract}
From the theoretical framework of french Discourse Analysis, we observed how the social, historical and ideological conditions affect the construction / formulation / circulation of the senses which can be naturalized, outlining a particular image on scholar library, reading and research. For this, we did a brief historical account on the development of the brazilian school libraries that was marked by senses of lack and restriction which are updated by the operation of discursive memory when they are reproduced in the contemporary discourse about this institution and the activities that are realized in its space. These senses show the importance of teachers and librarians change of attitude, make possible discoursive practices of reading and research that are more critical, creative and inquisitive, in the classroom and in the library, which is much more than a deposit or a collection of books.
\end{abstract}

Keywords

Discourse; Memory; School libraries; Reading; Scholar research 
"Logo pensei de escovar palavras. Porque eu havia lido em algum lugar que as palavras eram conchas de clamores antigos. Eu queria ir atrás dos clamores antigos que estariam guardados dentro das palavras. Eu já sabia também que as palavras possuem no corpo muitas oralidades remontadas e muitas significâncias remontadas." (Barros, 2003, p.1)

\section{Considerações iniciais}

Esse artigo é fruto de um projeto de pesquisa (Ferrarezi, 2010) cujo objetivo era, a partir de um diálogo entre os campos da Análise do Discurso e da Ciência da Informação, investigar como se dá a produção de sentidos sobre a biblioteca escolar, nas redes da Internet. Para tanto, foi fundamental perscrutarmos a historicidade dos dizeres sobre essa instituição, pois "a história está na língua. Esta é uma inscrição incontornável [...] não se pode ficar alheio a tal assertiva, sob pena de nos afastarmos do que toca mais de perto os domínios do discurso" (Ferreira, 2000, p.27). Sendo assim, temos que os dizeres sobre a biblioteca escolar são afetados pela história, pelo contexto em que são produzidos, bem como pela ideologia que naturaliza alguns discursos em detrimento de outros e, também, pela memória discursiva (1), que nos incita a seguir as pistas, os rastros de sentidos, que já haviam sido colocados em circulação e que agora são atualizados, constituindo uma determinada imagem de biblioteca escolar e das atividades nela realizadas, que é justamente o que buscamos investigar. Para tanto, apresentaremos, inicialmente, algumas considerações a respeito de como a biblioteca escolar foi constituída e significada, no contexto brasileiro, entremeando-nos, para tanto, às tramas da história e da memória, nas quais se enredam os sentidos que circulam, hoje, sobre essa instituição, trazendo à tona uma rede de já-ditos que sustenta também o vir-a-ser de outros.

\section{A biblioteca escolar brasileira: um percurso histórico}

Nessa seção, faremos um breve percurso buscando mobilizar os sentidos acerca da constituição e desenvolvimento das bibliotecas escolares no Brasil, aqueles que permanecem e retornam, pela memória discursiva, evocando efeitos de restrição, denunciando a inércia e precariedade que marcaram, desde o início, no século XVI, as bibliotecas escolares brasileiras. A partir de tais sentidos, as bibliotecas foram enunciadas como coleção de livros ou espaço físico, o que vai de encontro à concepção que atualmente se considerada como ideal, no campo da informação e da documentação. Como instrumento de poder controlado pelo clero ou pelo Estado, as bibliotecas carregam as marcas da histórica desigualdade de acesso, que deixou a maioria da população do lado de fora de seus portões.

No Brasil, a história das bibliotecas começou em 1549, com a vinda dos primeiros missionários jesuítas e dos livros trazidos por eles. Segundo Nascimento (2000, p. 2), "em 1583, no Colégio da Bahia, havia já uma boa biblioteca", chamada, na época, de livraria. Observamos a importância que era conferida a essa instituição e aos livros, visto que eles eram vistos como essenciais para a formação dos jesuítas; por conseguinte:

a sua falta prejudicava as atividades da ordem na catequese dos índios, assistência religiosa, ensino e educação dos colonos. E assim procuravam instalar livrarias em todos os seus estabelecimentos, desde os mais importantes, situados nas sedes da província até os mais modestos nas distantes aldeias. [...] As primeiras livrarias eram as dos colégios, que tiveram seu apogeu no século XVII e na primeira metade do XVIII. (Silva, 2008, p. 221)

Com as dificuldades de acesso às obras, os religiosos assumiram a função de copistas, confeccionando o que seriam os primeiros materiais didáticos produzidos no país. Sendo assim, a situação dos acervos das primeiras bibliotecas escolares era precária, havendo escassez e restrição do uso: 
Pela escassez de livros na Colônia e as dificuldades financeiras da Companhia de Jesus os acervos das bibliotecas dos colégios eram 'esmolados', isto é, doados à biblioteca quando da morte de algum padre. Esta dificuldade inviabilizava qualquer tipo de empréstimo aos escolares, pois acreditavam que 'para arruinar-se em pouco tempo uma biblioteca, basta emprestar os livros' (MORAES, 1979). Esse fato propiciou a ordenação, em 1589, de todos os livros existentes nas bibliotecas dos colégios' [...] Esse controle não se dava somente para evitar danos e furtos, mas, principalmente, para se saber quais livros deveriam ser lidos pelos alunos. (Castro, 2003, p. 65)

Instalaram-se, assim, práticas de controle que ainda hoje são encontradas em diversas bibliotecas escolares, de todo o país, que se mantém fechadas ou restringem a circulação de leitores e obras, consolidando ações que consideramos nocivas ao despertar do gosto de estar em uma biblioteca e entre os livros, delineando sentidos de cunho negativo para esta instituição. Conforme Silva (2008, p. 227), outra prática restritiva adotada era a censura das obras, pela qual "antes que fossem dispostos para consulta, os livros passavam por exame. Determinava-se que fossem corrigidos aqueles que contivessem conteúdo contrário à edificação e bons costumes”, instalando-se, assim, a política do silêncio, pela qual "se obriga a dizer 'x' para não deixar dizer 'y'." (Orlandi, 1997, p.83), a fim de que seja interditada a inscrição do sujeito em certas zonas da memória não-autorizadas.

Como nos conta Válio (1990), apesar das dificuldades, aos poucos, os acervos foram se multiplicando, tornando-se, entretanto, de uso particular dos jesuítas, visto que não havia no país nenhum outro tipo de biblioteca ou livraria que promovesse a formação de leitores; além disso, as exorbitantes taxas de analfabetismo também colaboravam para delinear este círculo fechado de leitores privilegiados. Entretanto, não houve mudanças positivas com a expulsão dos jesuítas, em 1579, pois as bibliotecas dos colégios foram praticamente abandonadas e muitas coleções foram saqueadas ou destruídas pela falta de conservação, conforme nos conta Silva (2008, p. 232):

Com a saída dos jesuítas, todos seus bens imóveis e móveis foram confiscados e tiveram destinos diversos. No que tange às bibliotecas e seus livros, veio a ocorrer um completo desmantelamento e desaparecimento dos acervos construídos ao longo de 200 anos. A história desse período, uma parte da história da destruição das bibliotecas no mundo, é ainda desconhecida.

A censura (política do silêncio), já praticada, enrijeceu-se e o acesso aos livros e outras fontes impressas só foi regularizado a partir de 1810, com a vinda da Corte Portuguesa ao Brasil. Após esse período, passou-se da censura religiosa à real, visando à interdição de quaisquer discursos considerados subversivos, perigosos. A partir da censura e outras práticas cerceadoras, a biblioteca escolar, no século XIX, atualizou práticas medievais que perduraram ao longo da história, evocando sentidos que a concebem como um lugar inacessível, sagrado e silencioso:

Tal como no período medieval, a prática da censura e os dispositivos do regulamento da biblioteca brasileira do século XIX a caracterizavam como o lugar 'augusto e sagrado', o espaço do silêncio, inacessível às camadas populares, simples e trabalhadoras. A elitização da leitura e do livro, as normas rígidas e proibitivas e a ausência da tradição bibliotecária vem permeando a humanidade por séculos a fio e, ainda hoje, em pleno século $X X I$, tem reflexos na maioria das escolas brasileiras onde a biblioteca escolar, quando existe, é o lugar do silêncio, o espaço do castigo. (Maroto, 2009, p. 18).

Durante a Primeira República (1889-1930), as bibliotecas continuaram sofrendo com falta de recursos e a postura limitada pela qual são concebidas apenas como estoques de materiais, depósitos de livros. As bibliotecas inauguradas no período, segundo Castro (2003), não foram frutos de iniciativas governamentais, mas de ações isoladas de professores. Inferimos que esse descaso do governo e a falta de práticas estruturadas são uma das causas da precariedade em que se encontram, ainda hoje, muitas bibliotecas escolares brasileiras. Voltando à nossa 
discussão, observamos que, após esse longo período de estagnação, na década de 1930, com as novas e mais amplas concepções educacionais que estavam em voga, surgiram discussões que valorizaram a biblioteca, atribuindo-Ihe um papel essencial para a educação. A partir delas:

iniciativas de promoção da leitura e de valorização da biblioteca começaram a surgir no país com a criação de bibliotecas infantis em alguns estados, além da instituição de programas e projetos de leitura, nas últimas décadas do século XX, desenvolvidos junto às escolas da rede oficial de ensino, e a outras instituições públicas e privadas comprometidas com a formação do leitor. (Maroto, 2009, p. 19)

Entretanto, segundo Castro (2003), essa breve movimentação em torno da biblioteca escolar foi encerrada no Estado Novo, que marcou o início da ditadura varguista (de 1937 a 1945) e novas ações em prol da censura, proibindo os livros que continham "ideologias subversivas" e promovendo aqueles que abordavam valores morais e patrióticos "adequados", que deveriam ser inculcados na população, através de sua distribuição. Assim sendo, destacou-se, neste período, a criação de uma política assistencialista que ainda é praticada, por meio da qual se distribuem livros às escolas e bibliotecas públicas. Consideramos que tais programas não foram suficientes para a instituição e desenvolvimento de bibliotecas escolares, visto que, para nós, estas não correspondem a apenas uma coleção de livros, muitas vezes dispostos em caixas, inertes e distantes da comunidade escolar.

Em seguida, houve uma nova tentativa de desenvolvimento das bibliotecas, que foi interrompida pela instauração de outra ditadura, mais rigorosa e repressora: a ditadura militar, que vigorou de 1964 a 1985 e se voltou para "a acomodação e para a alienação sócio-informacional, igualando-se ao período ditatorial de Vargas" (Castro, 2003, p.69). Também foi organizada uma política de distribuição de livros, por meio do Programa Nacional do Livro Didático, que visava à aquisição e distribuição de obras em bibliotecas escolares e universitárias. Entretanto, mais do que dotar as bibliotecas de recursos bibliográficos necessários à educação, estes programas assistencialistas contribuíram para o enriquecimento de editoras, sendo por esta razão extintos, pelo governo federal, em 1971, após a solicitação de observadores internacionais; foi nesta época que, segundo Castro (2003, p.69-70), a censura agravou-se:

Censura que rastreia o que deveria ser lido, estudado ou pesquisado, da educação infantil à educação superior. O Decreto 1077, de 6 de janeiro de 1971, do Ministro Alfredo Buzaid, determinava que a divulgação, leitura e acesso a livros e periódicos (nacionais e estrangeiros), em todos os níveis de ensino e em todas as bibliotecas, ficariam subordinados à verificação prévia da Polícia Federal a quem caberia analisar a existência de material ofensivo à moral e bons costumes.

Por fim, temos que, a partir dos anos 1980, com o término da ditadura militar e a abertura política, não houve um expressivo período de desenvolvimento das bibliotecas escolares, tendo sido engendrados pelo Estado uma vasta gama de "projetos desconexos e sem continuidade" (Castro, 2003, p.70), que não contribuíram para o diálogo entre ensino e biblioteca, o qual precisa ser fortalecido, por meio de ações sócio-governamentais que ultrapassem o enfoque restrito dado aos programas de criação de bibliotecas e seus acervos, os quais ganharam destaque com o advento da Lei no 12244 (Brasil, 2010a), que visa à universalização das bibliotecas nas instituições de ensino brasileiras. A seguir, falaremos um pouco sobre como, na atualidade, a produção de sentidos sobre a biblioteca escolar é afetada por essas condições sócio-histórico-ideológicas abordadas até aqui, que apontam para um quadro de dificuldades e ações equivocadas, cujos desdobramentos ainda podem ser observados, sustentado a atualização de determinados sentidos de biblioteca escolar que foram historicamente constituídos. 


\title{
3. A historicidade de um dizer sobre a biblioteca escolar: sentidos de falta e restrição
}

Em meio ao descaso, às dificuldades, à censura e uma série de práticas equivocadas, ganharam força os sentidos que sustentam a concepção de biblioteca como um espaço físico, um simples "aposento", ou como uma coleção de livros, retomando sentidos circulantes no período seiscentista:

\begin{abstract}
A primeira acepção é a mais clássica: 'Biblioteca: aposento ou lugar onde se colocam livros; galeria, construção cheia de livros. Diz-se também de livros que são geralmente arrumados sob construções compridas e em arcos'. Segue-se um segundo sentido que designa não mais um espaço, mas um livro: 'Biblioteca é também uma coleção, uma compilação de várias obras da mesma natureza, ou de autores que compilaram tudo que se pode dizer de um mesmo tema' (Dictionnaire de Furetière, 1690 apud Chartier, 1999, p.70, grifos nossos).
\end{abstract}

Essa forma reducionista de conceber a biblioteca, ao ser dicionarizada, afirma-se como um saber já-dado, digno de confiabilidade, que é legitimado como verdadeiro, apagando outros que poderiam estar em seu lugar. É interessante observarmos como, atualmente, apesar da emergência de discursos mais plurais sobre a biblioteca, esses sentidos restritivos são retomados pela memória discursiva, sendo concebidos como algo que se deve saber, como podemos notar na definição de "biblioteca" que é dada pelo dicionário Michaelis: "Coleção de livros, dispostos ordenadamente", "Estantes ocupadas por livros", ou ainda, "Edifício público ou particular onde se instalam grandes coleções de livros destinados à leitura de frequentadores ou sócios" (Trevisan, 1998). Ainda que esta última definição contemporânea mencione a leitura, sabemos que a biblioteca não pode ser concebida apenas a partir de seus aspectos físicos e materiais, sendo mais do que livros e um espaço pra leitura, visto que abrange uma série de outros materiais e atividades que a distanciam dessa visão restrita, que vem sendo atualizada, desde o século XVI, para significar as bibliotecas escolares brasileiras.

Estes sentidos seculares insistem em retornar nos discursos contemporâneos, sustentados pelas condições sóciohistóricas, que envolvem a falta de bibliotecas, recursos materiais, bibliográficos e de profissionais habilitados para nelas atuarem de modo mais crítico e interessante, indo além da organização e classificação dos materiais do acervo, o que implica conhecimento específico para mediá-lo de modo criativo para os seus leitores. (Ferrarezi \& Castro Filho, 2011), suplantando práticas que envolvem a restrição de uso das bibliotecas e de empréstimos de obras, a adoção de uma postura deveras autoritária, de regras muito rígidas que afastam os leitores, especialmente os mais jovens, dentre outras ações equivocadas que contribuem para a retomada de um já-dito referente aos sentidos de uma biblioteca tomada como sagrada, quase intocável, restrita a um pequeno número de privilegiados.

Assim, temos, conforme nos diz Milanesi (2002), um sistema que garante o acesso à educação formal, mas, na prática, o acesso à informação é negado. Observamos que é a partir da falta de acesso às instituições de ensino e às bibliotecas escolares que se dá a primeira forma de exclusão da esfera informacional, o que entendemos ferir um direito do cidadão e do sujeito-leitor:

Se a distribuição de riquezas materiais é injusta, mais ainda é a impossibilidade de acesso à informação - esta que seria o instrumento mais poderoso para superar condições que tornam os homens desiguais. Excluir a informação das necessidades básicas - vista às vezes como inútil ou perigosa é cortar pela raiz um direito sem o qual os indivíduos perdem outros. (Milanesi, 2002, p. 104-105)

Assim sendo, ao considerarmos o percentual de alunos de creche e educação infantil atendidos, observamos como ainda é muito pequena a oferta de bibliotecas (respectivamente 24,9\% e 33\%). (Brasil, 2009). A partir desses números, marcamos que a inexpressiva disponibilidade de bibliotecas para aqueles que estão iniciando a sua vida escolar afeta muito o desenvolvimento do gosto pela leitura, especialmente para os que não contam com livros e/ou não são estimulados no âmbito familiar, restando-lhes apenas as atividades realizadas na sala de aula, nem sempre suficientes e instigantes. Deste modo, será apenas no ensino fundamental e médio que um maior número de alunos 
poderá contar com uma biblioteca, ou seja, quando ele já foi afetado pelas práticas de leitura e pesquisa restritivas e monótonas, frequentemente praticadas nas salas de aula e sustentadas pelo foco no livro didático, que influenciarão o interesse pela biblioteca e o seu uso.

Entretanto, apesar dos índices relativos ao ensino fundamental serem um pouco maiores, "há necessidade de rápida ampliação no atendimento aos alunos no caso de recursos tais como biblioteca (57\%)" (Brasil, 2009, p.12). Dados mais recentes mostram que apenas $50 \%$ e $64,6 \%$ dos alunos contam, respectivamente, com bibliotecas nos anos iniciais e finais do ensino fundamental. (Brasil, 2010b). Destacamos, ainda, que as cifras mais otimistas referem-se ao ensino médio, onde $74,2 \%$ e $73,2 \%$ dos alunos contavam com acesso a bibliotecas, em 2009 e 2010, respectivamente. (Brasil, 2009, 2010b). De modo geral, esse quadro, que demonstra o descaso ainda conferido à biblioteca, pode ser melhor compreendido quando constatamos que a sua inexistência é uma realidade para 15 milhões de alunos, de escolas particulares e públicas (Weber, 2011). Esse número exorbitante pode indicar apenas parte do problema, posto que seria preciso avaliar que biblioteca escolar é essa que figura nas pesquisas, como ela é (ou não) organizada, utilizada e valorizada, bem como as obras, atividades e serviços que oferece, dentre outros aspectos que nos permitam ir além do aspecto quantitativo, dos sentidos dominantes que a consideram a partir do aspecto físico.

Esses questionamentos do que parece ser óbvio e exato, nos levam a apontar a importância da última edição da pesquisa "Retratos de leitura no Brasil", realizada pelo Instituto Pró-livro (2008, p. 15), a qual indicou que a existência de biblioteca não significa que ela seja adequada, nem frequentada, pois "muitos dos entrevistados sequer conhecem esse equipamento no bairro ou na cidade. [...] A essa desinformação, soma-se a incômoda indicação de que apenas $10 \%$ dos entrevistados frequentam assiduamente tal espaço", sendo que "3 em cada 4 brasileiros não vão a bibliotecas" (Instituto Pró-Livro, 2008, p. 94). Entre as causas para esse escasso uso de bibliotecas, $20 \%$ dos leitores alegaram que não as frequentam devido aos problemas que elas apresentam. Sendo assim, inferimos que o baixo uso de bibliotecas envolve uma série de questões, como a própria inexistência e o seu desconhecimento, a precariedade já citada, a falta de interesse, de estímulo e dificuldade de acesso à leitura e às bibliotecas, além de problemas ainda mais graves, como o analfabetismo e a baixa escolaridade, visto que "21 milhões dos que não lêem são analfabetos e 27 milhões só cursaram até a $4^{a}$ série do Ensino Fundamental." (Instituto Pró-Livro, 2008, p. 103).

Entre os leitores de livros, a biblioteca não é o local privilegiado, pois apenas 12\% realizam nela a leitura. Também foi apurado que a maioria dos leitores é constituída por estudantes, mais da metade são crianças e adolescentes, 0 que demonstra a relevância de que exista uma biblioteca escolar que atenda os alunos, professores e a comunidade, oferecendo o acesso a diversas obras e atividades sócio-educativas e culturais. É importante que tais atividades- de leitura, escrita, pesquisa etc- sejam dinâmicas, criativas e interessantes, estimulando o prazer de ler e frequentar outras bibliotecas, ao longo da vida, como as públicas, universitárias e comunitárias, delineando sentidos de biblioteca que se afastem daqueles relacionados a uma biblioteca escolar tradicional, arcaica, inerte e distante da comunidade escolar.

Todos esses dados estatísticos supracitados nos ajudam a compreender a importância da aprovação da Lei $\mathrm{n}^{0}$ 12244 (Brasil, 2010a); entretanto, consideramos que há ainda um longo caminho a ser percorrido, pois é preciso que se façam não apenas investimentos em estrutura e acervo das bibliotecas escolares, sendo também imprescindível que se abra, na escola e biblioteca, espaço para emergência de um sujeito que teça outra relação com a leitura, qual seja, como construção de sentidos, pois, acreditamos que o ato de ler "não se esgota na decodificação pura da palavra escrita ou da linguagem escrita" (Freire, 1989, p. 12). A seguir, teceremos mais algumas considerações a respeito das atividades de leitura e pesquisa desenvolvidas no âmbito escolar.

\section{Notas sobre a leitura e pesquisa no contexto escolar}

É importante que observemos o modo como a leitura e a pesquisa são geralmente motivadas ou silenciadas na sala de aula e na biblioteca escolar. No caso da leitura, destacamos a esporadicidade e o autoritarismo que a marcam: 
Na escola, em geral, a leitura nem sempre está em 'cartaz' e quando está, é apresentada em poucas 'sessões' e os 'ingressos' são oferecidos autoritariamente tendo como base o 'desejo da escola' e não o 'desejo coletivo'. Sendo assim, na maioria das vezes, não é possível considerar a escola como um espaço 'envolvente' e propício para a leitura. A leitura na escola ainda tem um ranço de didatismo. (Martins \& Bortolin, 2006, p. 38)

Sendo assim, Ferreira (2009, p.70) considera que o modo como as atividades de leitura são realizadas na sala de aula afastam os alunos de textos diversos; além disso, os estudantes, muitas vezes, não são estimulados a lerem e frequentarem a biblioteca:

Justifica-se, então, que esse espaço escolar seja pouco visitado pelos alunos e concebido por eles como aborrecido, monótono. Há, então, um porquê para a resistência dos alunos em relação à leitura e para o descaso em relação ao ensino de literatura e à biblioteca escolar.

Ainda segundo Ferreira (2009), em relação aos fatores que levam à rejeição da leitura, destacam-se a histórica ausência de uma prática democrática na sala de aula (impedindo o diálogo e a reflexão), a desvalorização da biblioteca, o livro entendido como instrumento de transmissão de normas, o pouco contato com os textos em casa e a falta de conhecimento dos professores em relação às obras infanto-juvenis. É importante ressaltarmos, também, como uma das causas dessa rejeição, a concepção de leitura como hábito, termo cujo uso nos incomoda, pois se relaciona a uma ação mecânica e desprovida de reflexão.

A partir desta região de sentidos, a leitura significaria um ato obrigatório e pouco fértil, exacerbado, muitas vezes, pela sua associação com punições e outras atividades cerceadoras e restritivas, como a de "estipular calendários (apenas uma ou duas vezes por semana) e fixar horários reduzidos” (Martins \& Bortolin, 2006, p. 39), que podem afastar os sujeitos-leitores, impedindo a circulação da imagem que associa leitura e prazer, a qual poderia estar presente em práticas onde o aluno tivesse maior liberdade para ir à biblioteca, perder-se entre as estantes e degustar um livro que mais the tenha chamado a atenção. Tais questões indiciam a necessidade de ações estruturais, mais amplas e planejadas, que se insiram no projeto educacional e abordem a leitura de forma a não vêla como mecânica, fechada, homogênea e autoritária, o que implica ir além do fornecimento de livros, como já dissemos anteriormente, já que "a simples distribuição de livros nas escolas não mudará, portanto, as práticas pedagógicas em relação ao uso de livros de literatura nem a apropriação e a construção de novos sentidos a partir da leitura." (Paiva \& Berenblum, 2009, p. 10).

Em relação à pesquisa escolar, inferimos que a forma como ela foi enraizada no sistema educacional, sendo ainda muito praticada, não colabora para o desenvolvimento de um processo educativo interessante e criativo, posto que, segundo Pieruccini (2008, p. 42), ela é vista como "resposta mecânica a solicitações- quase sempre também mecânicas- dos professores". Sendo assim, retomando Campello (2003, p.19), marcamos que atualmente "observase que a biblioteca ainda está afastada do processo de aprendizagem por meio da pesquisa escolar", na medida em que esta vem sendo usada apenas para complementar notas, ou, como forma de recuperação, caso elas estejam abaixo da média escolar (Ellwein, 2006). Marcamos também a relação distante estabelecida entre o atendente, o aluno e a tarefa pedida pelo professor:

As crianças, de um modo geral, são tratadas como escolares. Dessa forma, nas bibliotecas estabelece-se um diálogo triplo: o atendente, a criança e o professor- este representado por uma folha de caderno na qual está especificada a pesquisa a ser feita. A relação nesse caso passa a ser a do atendente com a folha de caderno. São as palavras aí contidas que definirão a busca. Como esse atendente não é especialista em literatura infantil e, muito menos, em criança, vale-se da primeira enciclopédia ao alcance das mãos e confere se existe algum verbete que se aproxima do assunto apontado na folha de caderno. Ao pequeno protagonista no papel de pesquisador cabe fazer uma cópia para desincumbir-se de uma tarefa. Ele está ali para cumprir uma obrigação para ser aprovado. E como há muito mais obrigações a cumprir do que prazer a ser buscado, existem 
mais bibliotecas escolares do que infantis. E conforme o quadro econômico-social, nem mesmo existe a biblioteca escolar ou o que pode ser assim chamado. (Milanesi, 2002, p.57).

Ao ocuparem a posição de escolares, é associada aos sujeitos-alunos uma imagem estereotipada, pela qual eles teriam as mesmas preferências e interesses de leitura, atribuindo os mesmos sentidos ao que lêem; além disso, a partir dessa proposta de "roteirização" homogeneizadora (Coracini, 1999), os sujeitos teriam que ler as mesmas obras que os demais, escrever exatamente o que se pede, repetindo os sentidos veiculados pelos professores e os livros. Inferimos que as atividades educativas autoritárias e parafrásticas, centradas exclusivamente no livro didático e realizadas no âmbito da escola e sua biblioteca "tradicional" (quando esta existe), tendem a serem vistas como desinteressantes e monótonas, por sujeitos-navegadores das ágeis, múltiplas e interativas redes eletrônicas, que carregam a promessa de liberdade para aquele que nelas navega.

É importante ressaltarmos também que, na ausência de uma prática educacional mais crítica, que leve em conta a constituição dos saberes, e não a sua mera reprodução, instigando os alunos a interpretarem os discursos materializados no suporte impresso e, também, digital, os estudantes acabam usando a Internet da mesma maneira infrutífera que as enciclopédias impressas foram e ainda continuam sendo utilizadas: copiando os fragmentos (agora dispersos pela rede eletrônica) a serem entregues ao professor (não mais escritos à mão ou datilografados, mas impressos), o que também é apontado por Garcez (2009, p. 21): "mesmo com todas as informações disponibilizadas na Internet, os alunos, não sabem fazer pesquisa diferente da mera cópia, e agora no atualizado recorta-e-cola, que os processadores eletrônicos de textos tornou possível."

Compreendemos que, por meio de tais práticas, os sujeitos-alunos acabam não ocupando a posição de autor (Orlandi, 1988), nem a função-leitor (Pacífico, 2002), que o permitiriam assumir a responsabilidade pelo seu dizer e duvidar da transparência da linguagem, buscando compreender a constituição dos sentidos e realizar uma leitura mais polissêmica, em um contexto marcado pela "superabundância textual cuja oferta ultrapassa a capacidade de apropriação dos leitores" (Chartier, 2002, p. 20). Por conseguinte, os sujeitos acham-se:

numa situação em que tudo Ihes é estranho, parecendo marinheiros sem bússola, lançados à deriva nos oceanos informacionais (e do conhecimento). Em decorrência e sob tais circunstâncias, os atos de conhecer e de significar encontram-se afetados diretamente, demandando ações visando sua requalificação e reafirmação nos contextos contemporâneos, dentre as quais se inclui uma nova abordagem da biblioteca escolar. (Pieruccini, 2008, p.44)

É importante ressaltarmos, ainda, que as bibliotecas não foram preparadas para atender a pesquisa escolar, que foi instituída legalmente na década de 1970, levando muitos alunos a procurarem as bibliotecas públicas que, no entanto, também não estão aptas a atendê-los, pois possuem orientação e estrutura muito diversa. Da mesma maneira, "os professores não foram preparados para lidar com essa nova exigência; a preparação não existia no currículo dos cursos formadores de profissionais como também não estava estruturada nas estâncias educacionais do Estado. É possível que uma ou outra iniciativa tenha ocorrido, mas não redundaram em uma prática comum" (Almeida Júnior, 2006, p. 98-99). Observamos, conforme já adiantamos, que, nos últimos anos, nos quais se destacou o advento da Internet, poucas mudanças ocorreram:

causando uma sensação de derrota naquele que pesquisa (aluno), no que solicita a pesquisa (professor), em que tenta orientá-la (bibliotecário) e, ainda, nos que, quando interessados, acompanham a pesquisa (pais e/ou responsáveis). (Almeida Júnior\& Bortolin, 2009, p. 213).

Quando se fala em pesquisa escolar na Internet, uma prática que ganha cada vez mais força, é preciso considerar que há realidades muito distintas de acesso: "De um lado há uma parcela de estudantes que possui equipamentos, conhecimentos e habilidades para acesso às informações contidas na web. Do outro lado estão os estudantes 
desprovidos até de material impresso para a pesquisa." (Bicheri \& Ellwein, 2006, p. 106). Afetados pela ideologia que legitima as novas tecnologias de informação, como a Internet, os sujeitos-alunos julgam que os sentidos em circulação na Web são corretos e os únicos possíveis, selecionando e imprimindo, muitas vezes, sem ao menos ler, as primeiras informações que correspondam ao tema proposto.

Destacamos que, a partir das práticas restritivas citadas, a Internet seria vista, pelos sujeitos-alunos que nela navegam, apenas como um repositório de informações prontas, acabadas, verdadeiras, que podem ser recortadas sem se levar em conta o viés político e ideológico que constituem os dizeres, a incompletude e heterogeneidade, que reclamam gestos de interpretação, uma leitura que vai além do literal. Como apontamos, as ferramentas oferecidas pelo meio eletrônico tornam mais fáceis e ágeis as operações de pesquisa, cópia e seleção do que será impresso e entregue ao professor, estruturando a aprendizagem em redes de paráfrases que impedem o surgimento do novo, o que nos faz concordar com Bicheri e Ellwein (2006), quando afirmam que não basta apenas saber manusear as tecnologias, mas valer-se de suas funcionalidades para tecer uma relação mais criativa com o saber.

Analogamente, constituir uma biblioteca com um ambiente agradável e bem iluminado, dotada de um acervo diversificado e móveis adequados ao uso que deles será feito não significa, necessariamente, criar um espaço polissêmico que concretize a concepção de biblioteca em que acreditamos. A existência destes recursos pode ser muito profícua, contudo cabe observarmos que, muitas vezes, bibliotecas menos equipadas, mas que contam com profissionais abertos a práticas que se distanciem daquelas tradicionalmente realizadas na sala de aula, podem configurar-se de maneira mais próxima da que é considerada ideal.

Isso nos faz reforçar a importância da formação de profissionais que contribuam para a superação das atividades de pesquisa como cópia e leitura como mero processo de decodificação do que "o autor quis dizer", associadas ao uso da biblioteca como se esta fosse um mero apêndice, depósito ou lugar de castigo. Diante da forma infrutífera de lidar com a leitura e a pesquisa escolar, tanto em materiais impressos quanto eletrônicos, é preciso uma mudança de postura por parte dos professores e bibliotecários, abrindo espaço para práticas discursivas mais criativas e questionadoras, como viemos sugerir, apoiadas nos pressupostos teóricos da Análise do Discurso francesa. Neste contexto, pode ser construído um espaço discursivo plural e movimentado, de produção de sentidos outros, no qual é dada ao sujeito a possibilidade de tecer o novo, "possibilitando-lhe agir no mundo e não ser apenas um receptor de sentidos estereotipados" (Romão \& Pacífico, 2006, p. 10).

Posto isto, podemos inferir que as questões de acesso à informação, aos bens culturais e aos espaços de leitura vão muito mais além da existência de instituições como as bibliotecas, sendo necessárias também ações que as incluam e signifiquem no contexto escolar, passando de uma postura inerte para a de agente num processo de ensino/aprendizagem mais criativo, que possa romper com os sentidos de desigualdade, restrição e censura historicamente atribuídos às bibliotecas, bem como às práticas que nela são realizadas, a fim de tecer outra redes de sentidos, a partir da emergência do novo, do acontecimento, "rompendo o círculo da repetição", como propõe Pêcheux (1990, p.16). 


\section{Referências}

Almeida Júnior, O. F. (2006). Pesquisa escolar: entre o modelo educacional e a liberdade da pesquisa. In: Silva, R. J., \& Bortolin, S. (Orgs.). Fazeres cotidianos na biblioteca escolar. São Paulo: Polis.

Almeida Júnior, O. F. \& Bortolin, S. (2009). Bibliotecário: um essencial mediador de leitura. In: Souza, R. J. (Org.). Biblioteca escolar e práticas educativas. Campinas: Mercado de Letras.

Barros, M. (2003). Memórias inventadas: a infância. São Paulo: Planeta.

Bicheri, A. L. A. O. \& Ellwein, S. A. F. (2006). Pesquisa escolar na Internet. In: Silva, R. J. \& Bortolin, S. (Orgs.). Fazeres cotidianos na biblioteca escolar. São Paulo: Polis.

Brasil. (2010a). Lei no 12244, de 24 de maio de 2010. Dispõe sobre a universalização das bibliotecas nas instituições de ensino do País. Diário Oficial da União, Brasília. Recuperado em 17 de outubro de 2011, de http://www.jusbrasil.com.br/diarios/5259000/dou-secao-1-25-05-2010-pg-3

Brasil. (2010b). Resumo técnico- Censo escolar 2010. Recuperado em 23 de novembro de 2011, de http://download.inep.gov.br/educacao basica/censo escolar/resumos tecnicos/divulgacao censo2010 revisao 04022011.pdf

Brasil. Ministério da Educação. Instituto Nacional de Estudos e Pesquisas Educacionais. (2009). Resultados do Censo da Educação Básica 2009. Recuperado em 5 de setembro de 2011, de

http://download.inep.gov.br/download/censo/2009/TEXTO DIVULGACAO EDUCACENSO 20093.pdf

Campello, B. S. (2003). A função educativa da biblioteca escolar no Brasil: perspectivas para seu aperfeiçoamento. In 5 Encontro Nacional de Pesquisa em Ciência da Informação. Belo Horizonte: Escola de Ciência da Informação da UFMG. Recuperado em 19 de setembro de 2011, de http://gebe.eci.ufmg.br/downloads/ENAN054.pdf

Castro, C. A. (2003). Ensino e biblioteca: diálogo possível. Transinformação, Campinas, 15 (1), 63-72, jan./abr. Recuperado em 14 de outubro de 2011, de http://revistas.puccampinas.edu.br/transinfo/include/getdoc. . hp? $\mathrm{id}=52 \&$ article=15\&mode=pdf\&OJSSID=02a64d737401fbc089988ffc389c04bf

Chartier, R. (1999). A ordem dos livros: leitores, autores e bibliotecas na Europa entre os séculos XIV e XVIII. 2.ed. Brasília: Editora Universidade de Brasília.

Chartier, R. (2002). Os desafios da escrita. Tradução de Fúlvia M. L. Moretto. São Paulo: Editora UNESP.

Coracini, M. J. (1999). A produção textual em sala de aula e a identidade do autor. In: Leffa, V. J. \& Pereira, A. E. (Orgs.). O ensino da leitura e produção textual: alternativas de renovação. Pelotas: EDUCAT.

Ellwein, S. A. F. (2006). Pesquisa escolar e enfadonho exercício de cópia: como separar o trigo do joio? In: Silva, R. J. \& Bortolin, S. (Orgs.). Fazeres cotidianos na biblioteca escolar. São Paulo: Polis.

Ferrarezi, L. (2010). A biblioteca escolar nas teias do discurso eletrônico. 2010. Dissertação (Mestrado em Ciências) - Faculdade de Filosofia Ciências e Letras de Ribeirão Preto, Universidade de São Paulo, Ribeirão Preto.

Ferrarezi, L. \& Castro Filho, C. M. (2011). Atuação profissional na biblioteca escolar: outras perspectivas. In: Castro Filho, C. M. \& Romão, L. M. S. (Orgs.). Dizeres sobre biblioteca escolar: palavras em movimento. Ribeirão Preto: Alphabeto.9-120.

Ferreira, E. A. G. R. (2009). A leitura dialógica como elemento de articulação no interior de uma biblioteca vivida. In: Souza, R. J. (Org.). Biblioteca escolar e práticas educativas. Campinas: Mercado de Letras.

Ferreira, M. C. L. (2000). Da ambiguidade ao equívoco: a resistência da língua nos limites da sintaxe e do discurso. Porto Alegre: Editora da Universidade/UFRGS

Freire, P. (1989). A importância do ato de ler: em três artigos que se completam. São Paulo: Cortez.

Garcez, E. F. (2009). Sociedade da informação e escola: contribuição das bibliotecas escolares. ACB, 14 (1), 9-26, jan./jun. Recuperado em 10 de agosto de 2011, de http://revista.acbsc.org.br/index.php/racb/article/download/653/721

Instituto Pró-Livro. (2008). Retratos de leitura no Brasil. Recuperado em 10 de agosto de 2011, de http://www.prolivro.org.br/ipl/publier4.0/dados/anexos/48.pdf

Maroto, L. H. (2009). Biblioteca escolar, eis a questão!: do espaço do castigo ao centro do fazer educativo. Belo Horizonte: Autêntica. 
Martins, E. \& Bortolin, S. (2006). O bibliotecário escolar 'afinando' o foco na leitura. In: Silva, R. J. \& Bortolin, S. (Orgs.). Fazeres cotidianos na biblioteca escolar. São Paulo: Polis.

Milanesi, L. (2002). Biblioteca. Cotia, SP: Ateliê Editorial.

Nascimento, J. C. (2000). Nota prévia sobre a palavra impressa no Brasil do século XIX- A biblioteca do povo e das escolas. In: 1 Congresso Brasileiro de História da Educação. Rio de Janeiro: Sociedade Brasileira de História da Educação. Recuperado em 20 de outubro de 2011, de http://www.sbhe.org.br/novo/congressos/cbhe1/anais/074 jorge carvalho.pdf

Orlandi, E. P. (1988). Nem escritor, nem sujeito: apenas autor. In: Discurso e leitura. Campinas: Editora da Unicamp.

Orlandi, E. P. (1997). As formas do silêncio: no movimento dos sentidos. 4.ed. Campinas: Editora da UNICAMP. (Coleção

Repertórios).

Pacífico, S. M. R. (2002). Argumentação e autoria: o silenciamento do dizer. 2002. Tese (Doutorado)- Faculdade de Filosofia, Ciências e Letras de Ribeirão Preto, Universidade de São Paulo, Ribeirão Preto.

Paiva, J. \& Berenblum, A. (2009). Programa Nacional Biblioteca da Escola (PNBE)- uma avaliação diagnóstica, Pro-Posições, Campinas, 20 (1), 173-188, jan./abr. Recuperado em 20 de setembro de 2011, de http://mail.fae.unicamp.br/ proposicoes/textos/58-artigos-paivaj etal.pdf

Pêcheux, M. (1990). Delimitações, inversões, deslocamentos. Tradução de José Horta Nunes. Cadernos de Estudos Linguísticos, Campinas, 19, 7-24, jul./dez.

Pêcheux, M. (1997). Semântica e Discurso: uma crítica à afirmação do óbvio. Tradução de Eni Pulcinelli Orlandi et al. 3. ed. Campinas, SP: Editora da UNICAMP.

Pêcheux, M. (1999). Papel da memória. In: Achard, P. et al. Papel da memória. Tradução de José Horta Nunes. Campinas: Pontes.

Pêcheux, M. (2002). O discurso: estrutura ou acontecimento. Tradução de Eni Puccinelli Orlandi. 3.ed. Campinas: Pontes.

Pieruccini, I. (2008). Biblioteca escolar, pesquisa e construção do conhecimento. In: Romão, L. M. S. (Org.). Sentidos da biblioteca escolar. São Carlos: Gráfica e Editora Compacta.

Romão, L. M. \& Pacífico, S. M. R. (2006). Era uma vez uma outra história: leitura e interpretação na sala de aula. São Paulo: DCL.

Silva, L. A. G. (2008). As bibliotecas dos jesuítas: uma visão a partir da obra de Serafim Leite. Perspectivas em Ciência da Informação, 13 (2), 219-237, maio/ago. Recuperado em 10 de agosto de 2011, de

http://www.scielo.br/scielo.php?script=sci arttext\&pid=S1413-99362008000200014

Trevisan, R. (Coord.). (1998). Michaelis: moderno dicionário da língua portuguesa. São Paulo: Editora Melhoramentos.

Válio, E. B. M. (1990). Biblioteca escolar: uma visão histórica. Transinformação, Campinas, 2 (1), 15-24, jan./abr.

Weber, D. (2011). Quinze milhões de alunos estudam em escolas sem biblioteca no país. O Globo, 29 jan. Recuperado em 10 de outubro de 2011, de http://oglobo.globo.com/politica/quinze-milhoes-de-alunos-estudam-em-escolas-sem-biblioteca-no-pais2830788

\section{Notas}

(1) Para a Análise do Discurso de linha pêcheuxtiana, a memória discursiva diz respeito a uma rede de dizeres que já foram ditos e esquecidos, mas que, no momento da enunciação, são retomados inconscientemente pelo sujeito, sustentando e (res)significando aquilo que ele diz, que pode ser repetido, ou, deslocado, abrindo espaço para a polissemia, para outros sentidos possíveis a partir do mesmo. (Pêcheux, 1997, 1999, 2002) 


\section{Dados das autoras}

\section{Ludmila Ferrarezi}

Doutoranda e Mestre em Ciências, pela Faculdade de Filosofia, Ciências e Letras de Ribeirão Preto da Universidade de São Paulo (FFCLRP/USP). Bacharel em Ciências da Informação e da Documentação e Biblioteconomia pela mesma instituição. É membro do GEL, da ABEHTE, do grupo de pesquisa "Discurso e Memória: nos movimentos do sujeito", cadastrado no CNPQ e do E-L@DIS- Laboratório discursivo (FAPESP). Bolsista da FAPESP.

ludmila.ferrarezi@gmail.com

\section{Lucília Maria Sousa Romão}

Livre-Docente em Ciências da Informação e da Documentação É professora do Programa de Pós-Graduação em Psicologia e da Graduação em Ciências da Informação e da Documentação na Faculdade de Filosofia, Ciências e Letras de Ribeirão Preto da Universidade de São Paulo. Professora colaboradora do Programa de Pós-Graduação em Ciência, Tecnologia e Sociedade, na Universidade Federal de São Carlos. Coordenadora do E-|@disLaboratório discursivo (FAPESP).

luciliamsr@uol.com.br

Recibido - Received: 2012-02-02

Aceptado - Accepted: 2012-03-30

\section{(cc) EY-NC-ND}

This work is licensed under a Creative Commons

Attribution-Noncommercial-No Derivative Works 3.0 United States License.

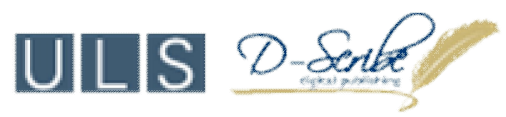

This journal is published by the University Library System of the University of Pittsburgh as part of its $\underline{D-S c r i b e}$ Digital Publishing Program and is cosponsored by the University of Pittsburgh Press. 